\title{
Granitos Peraluminosos da Porção Central da Faixa Ribeira, Estado de São Paulo: Sucessivos Eventos de Reciclagem da Crosta Continental no Neoproterozóico
}

\author{
Valdecir de Assis Janasi ${ }^{1}$ (vajanasi@usp.br), Adriana Alves², Silvio Roberto Farias Vlach ${ }^{1}$, Renato Jordan Leite ${ }^{3}$ \\ ${ }^{1}$ Departamento de Mineralogia e Geotectônica - Instituto de G eociências - USP \\ R. do Lago 562, CEP 05508-080, São Paulo, SP, BRA \\ ${ }^{2} \mathrm{G}$ raduação em Geologia - Instituto de G eociências - USP, São Paulo, SP, BRA \\ ${ }^{3}$ Programa de Pós-Graduação em Mineralogia e Petrologia - Instituto de G eociências - USP, São Paulo, SP, BRA
}

Palavras-chave: monazita, geocronologia U-Pb, granito, Faixa Ribeira.

\section{RESUMO}

O Domínio Embu, na porção central da Faixa Ribeira no Estado de São Paulo, abriga inúmeras ocorrências de intrusões graníticas neoproterozóicas. Peculiar é a abundância de granitos marginal a francamente peraluminosos, que formam dezenas de ocorrências menores, e mesmo alguns batólitos, especialmente na região a leste da cidade de São Paulo. As variedades petrográficas mais comuns incluem biotita granitos porfiríticos, biotita-muscovita leucogranitos brancos e turmalina-granada granitos. Datações U-Pb em monazita obtidas em anos recentes têm revelado que, a despeito da similaridade petrográfica, esses granitos foram gerados em diversos eventos geológicos que se sucederam em um intervalo de pelo menos $\mathrm{ca}$. 200 milhões de anos, ao final do Neoproterozóico. As idades mais antigas, da ordem de 780 Ma, têm sido obtidas em ortognaisses peraluminosos, alguns ricos em minerais máficos e muscovita, e em alguns aspectos similares a típicos granitos " $\mathrm{S}$ ". Dados preliminares obtidos em monazitas do batólito Serra do Quebra-Cangalha fornecem idade de ca. $680 \mathrm{Ma}$, mostrando ser ele significativamente mais antigo que a principal manifestação do magmatismo cálcio-alcalino no domínio Embu (o batólito Agudos Grandes, com 610 $600 \mathrm{Ma}$ ). Os leucogranitos peraluminosos tipo Turvo, datados em $610 \pm 2 \mathrm{Ma}$, se associam à fusão crustal durante este último evento. Diferentes manifestações graníticas de menor porte situadas no Domínio Embu a leste da cidade de São Paulo têm fornecido idades U-Pb em monazita no intervalo 580 - 590 Ma (maciços Mauá, Mogi das Cruzes, Jaguari). Idade similar foi obtida para a cristalização do batólito Natividade da Serra, no Domínio Costeiro ( $587 \pm 5 \mathrm{Ma}$ ). Essas idades coincidem com o pico do magmatismo granítico da orogênese Rio Doce na porção oriental da Faixa Ribeira. Idades U-Pb ainda mais jovens ( 540 Ma) foram obtidas em monazita de um muscovita-biotita granito do maciço Santa Branca; seu significado, no entanto, é ainda duvidoso, dado o caráter fortemente discordante dos resultados analíticos.

Keywords: monazite, U-Pb geochronology, granite, Ribeira Belt.

\section{ABSTRACT}

The Embu Domain, central portion of the Ribeira Fold Belt in the State of São Paulo, includes a large number of Neoproterozoic granitic plutons. A peculiar feature is the abundance of marginal to strongly peraluminous granites, which comprise dozens of minor occurrences and also some batholiths, especially in the region east of the city of São Paulo. The more common petrographic varieties are biotite granite, white biotite-muscovite leucogranite and tourmaline-garnet granites. Recent monazite $\mathrm{U}-\mathrm{Pb}$ dating has revealed that, in spite of the petrographic similarities, these granites were generated in several successive geological events that occurred over a ca. 200-million-year time interval at the end of Neoproterozoic. The oldest ages, around $780 \mathrm{Ma}$, are from peraluminous orthogneisses, some rich in mafic minerals and muscovite and in some respects similar to typical "S-type" granites. Preliminary data from the Serra do Quebra-Cangalha batholith yield a U-Pb monazite age of $c a$. 680 $\mathrm{Ma}$, revealing it to be significantly older than the main manifestation of calc-alkaline magmatism in the Embu Domain (the Agudos Grandes batholith, $610-600 \mathrm{Ma}$ in age). The Turvo-type peraluminous leucogranites, dated at $610 \pm 2 \mathrm{Ma}$, are 
associated with crustal melting during the latter event. Different smaller granitic occurrences located in the Embu Domain east of the city of São Paulo yield U-Pb monazite ages in the 590 - 580 Ma range (Mauá, Mogi das Cruzes, Jaguari massifs). A similar age was obtained for the magmatic crystallization of the Natividade da Serra batholith in the Costeiro Domain ( $587 \pm 5 \mathrm{Ma})$. These ages are coincident with the peak in granitic magmatism of the Rio Doce orogeny in the eastern portion of the Ribeira Belt. An even younger U-Pb age ( $\sim 540 \mathrm{Ma})$ was obtained in a sample from the Santa Branca muscovite-biotite granite; its meaning, however, is still uncertain, given the strongly discordant character of the analytical results.

\section{INTRO DUÇÃO}

Granitos marginal a fortemente peraluminosos são abundantes no Domínio Embu, porção central da Faixa Ribeira no Estado de São Paulo, formando dezenas de ocorrências menores, e mesmo alguns batólitos expressivos de idade neoproterozóica. A participação predominante ou exclusiva de material derivado da crosta continental é sugerida pelo caráter fracionado das facies dominantes, ou, em casos de rochas ricas em máficos, pelo caráter francamente peraluminoso das rochas. Determinações isotópicas $\mathrm{Sm} / \mathrm{Nd}$ indicam que esses granitos derivam principalmente da reciclagem de crosta continental antiga, dominantemente paleoproterozóica; componentes mantélicos neoproterozóicos são ausentes ou subordinados.

Determinações precisas da idade desses granitos são ainda escassas e estiveram restritas, até recentemente, a idades isocrônicas $\mathrm{Rb}-\mathrm{Sr}$ em rocha total, que carregam largas incertezas, e em alguns casos podem fornecer resultados distintos da idade de cristalização da rocha, por exemplo refletindo a presença de componentes restíticos. $\mathrm{O}$ emprego de datações U-Pb em zircão também pode não fornecer idades de cristalização magmática, devido à ocorrência comum de herança em magmas crustais de baixa temperatura. Nesses casos, a datação U-Pb de monazita pode mostrar melhores resultados, em vista da temperatura de fechamento desse mineral $\left(\sim 700^{\circ} \mathrm{C}\right)$, compatível com a temperatura de cristalização dos leucogranitos, e dos baixos coeficientes de difusão do $\mathrm{Pb}$ abaixo dessa temperatura, de modo que as idades obtidas são comumente concordantes (e. g., Parrish, 1990).

Ocorrências selecionadas de granitos peraluminosos aflorantes nos Domínios Embu e Costeiro no Estado de São Paulo têm sido alvo de determinações U-Pb em monazita pelos autores, envolvendo diversas metodologias (espectrometria de massa por ionização térmica-TIMS e microssonda eletrônica-EPMA) e laboratórios (CPGeo e Laboratório de Microssonda Eletrônica do Instituto de Geociências da USP, Isotope Geochemistry Laboratory da Universidade do Kansas, EUA, e Laboratório U-Pb da Universidade de Alberta, Canadá). No presente artigo, são apresentados resultados iniciais de um projeto analítico ainda em curso de determinações U-Pb em monazita por TIMS junto ao CPGeo, que são discutidos no contexto oferecido por um universo maior de dados, fornecidos por outros laboratórios, em parte ainda inéditos ou em fase de publicação.

\section{O MAGMATISMO GRANÍTICO NA PORÇÃO CENTRAL DA FAIXA RIBEIRA}

O magmatismo granítico é bastante expressivo por toda a Faixa Ribeira; a caracterização adequada e o entendimento do significado desse magmatismo são parte fundamental de qualquer modelo evolutivo para a Faixa. Entre as diversas abordagens que têm sido adotadas por pesquisadores de diversas instituições brasileiras e estrangeiras, destacamse os esforços para a definição da estratigrafia do magmatismo granítico e para a compreensão dos processos petrológicos e tectônicos responsáveis pela geração desses magmas (e. g., Hasui et al., 1978; Janasi \& Ulbrich, 1991; Machado et al., 1996; Tupinambá, 1999).

Uma porção de extensão ainda desconhecida da Faixa Ribeira é constituída por embasamento com idades superiores a $2 \mathrm{Ga}$, que foi retrabalhado em graus variados no Neoproterozóico. A Faixa é composta por diversos domínios tectonicamente limitados e de relações mútuas ainda incertas; em função disto, uma nomenclatura de "terrenos" tem sido adotada pela maioria dos autores para descrever o seu arranjo. Dados isotópicos Sm-Nd recentes, e ainda escassos, sugerem que uma divisão maior pode ser reconhecida na Faixa Ribeira, correspondendo grosseiramente aos Terrenos Ocidental e Oriental de Heilbron et al. (1999). No Terreno Ocidental, que inclui os Terrenos Juiz de Fora, Embu e Apiaí de Campos Neto \& Figueiredo (1995), as idadesmodelo Sm-Nd são tipicamente de 2,0 Ga ou mais velhas (Reis Neto, 1994; Sato, 1998); no Terreno Oriental, que corresponde a Microplaca Serra do Mar de Campos Neto \& Figueiredo (1995) idades-modelo Sm-Nd mais baixas (usualmente no intervalo 1,3 - 1,7 Ga) são observadas em metassedimentos e em granitos cálcio-alcalinos e peraluminosos (Sato, 1998; Tupinambá, 1999).

A datação de granitos pelo método U-Pb tem se mostrado, em anos recentes, uma das ferramentas mais importantes para o entendimento da evolução geológica da Faixa 
Ribeira. Dadas às dificuldades para datação absoluta das rochas supracrustais, e os contatos freqüentemente tectônicos ou não expostos entre as diferentes seqüências supracrustais ou de embasamento, têm sido as idades dos granitos sin-orogênicos os principais marcadores dos eventos tectonometamórficos registrados na Faixa.

Os primeiros dados U-Pb obtidos de maneira sistemática foram apresentados para granitóides e rochas de alto grau metamórfico do extremo NE da Faixa (e. g., Sölner et al., 1987); as idades obtidas para batólitos graníticos cálcioalcalinos, granitos peraluminosos sin-colisionais e para o metamorfismo principal se situaram entre 580 e $560 \mathrm{Ma}$. Campos Neto \& Figueiredo (1995) utilizaram esses dados para caracterizar uma orogênese Neoproterozóica importante nesse segmento da Faixa Ribeira por eles designada "Rio Doce".

Um intervalo de idades similar (590 - $565 \mathrm{Ma}$ ) foi identificado para o metamorfismo M1 na porção central da Faixa Ribeira, na região oeste do Estado do Rio de Janeiro e áreas adjacentes em Minas Gerais (Machado et al., 1996). Esses autores caracterizaram ainda um segundo evento metamórfico (M2), restrito aos Domínios Costeiro e Paraíba do Sul (correspondentes ao Terreno Oriental de Heilbron et al., 1999), a 535 - 520 Ma.

Entre as principais ocorrências de rochas graníticas que foram alvo de estudos geocronológicos de algum detalhe na Faixa Ribeira, destacam-se os batólitos Serra dos Órgãos, Agudos Grandes e Três Córregos.

A estratigrafia do Batólito Serra dos Órgãos foi estudada por Tupinambá (1999). Um conjunto de ortognaisses de composição dominantemente tonalítica (o Complexo Rio Negro) foi datado em $634 \pm 10 \mathrm{Ma}$ (U-Pb em zircão; TIMS); essa idade é a mais antiga obtida até o momento para rochas graníticas nessa região da Faixa Ribeira, e é interpretada pelo autor como anterior ao primeiro evento metamórfico, época da instalação de um arco magmático continental. Leucogranitos gnáissicos intrusivos nessas rochas foram datados no intervalo 600 - $590 \mathrm{Ma}(\mathrm{Pb}-\mathrm{Pb}$, evaporação de zircão). A idade da fase magmática principal (Serra dos Órgãos s.s.) foi investigada pelo mesmo método $(580 \pm 17 \mathrm{Ma})$ e também por TIMS. De acordo com a interpretação do autor, os dados obtidos por TIMS forneceriam idades mais jovens (560 - 550 Ma), mas as idades das frações mais precisas e isentas de herança sugerem valores similares ao obtido por evaporação de zircão (580 - $590 \mathrm{Ma})$. Valores nesse intervalo posicionam a idade da fase magmática principal, sin-metamórfica, do Batólito Serra dos Órgãos, no mesmo intervalo obtido para o metamorfismo M1 por Machado et al. (1996). Apenas idades Rb-Sr estão disponíveis para o magmatismo pós-orogênico nessa região; os dados obti- dos por Tupinambá (1999) indicaram idades de $560 \pm 23 \mathrm{Ma}$ (granitos porfiríticos predominantes) e $547 \pm 8 \mathrm{Ma}$ (leucogranitos tardios).

Datações U-Pb em zircão e monazita foram obtidas recentemente em amostras representativas de alguns dos principais tipos de granitos constituintes do Batólito Agudos Grandes (Janasi et al., 2001). Hornblenda-biotita granitos porfiríticos, que constituem a variedade petrográfica mais abundante entre os granitos sin-orogênicos do batólito (tipo Ibiúna), foram datados em $610 \pm 2 \mathrm{Ma}$; essa idade é idêntica à obtida para monazita de um tipo petrográfico fortemente contrastado, e neles intrusivo, o muscovita-biotita leucogranito Turvo $(610 \pm 1 \mathrm{Ma})$. O magmatismo tardiorogênico do batólito é cerca de 5 - 10 Ma mais jovem, como demonstrado pelas datações obtidas no maciço granítico Piedade (três idades U-Pb, variáveis entre 601 e $605 \mathrm{Ma}$ ). O magmatismo pós-orogênico, representado pelo maciço Serra da Batéia, com características geoquímicas de granitos de tipo A, é significativamente mais jovem $(564 \pm 8 \mathrm{Ma})$.

Determinações U-Pb obtidas em diferentes amostras de granitos cálcio-alcalinos do batólito Três Córregos indicaram idades similares às observadas no batólito Agudos Grandes (605 - 610 Ma) (Gimenez Filho et al., 2000; ver também Prazeres Filho, 2000). Essas idades mostram não ter significado o amplo intervalo de tempo previamente sugerido para a geração do batólito com base em datações Rb-Sr (750 - 640 Ma; Gimenez Filho, 1993). Por outro lado, destacam o caráter um pouco mais antigo do evento magmático gerador dos grandes batólitos cálcio-alcalinos na porção centro-sul da Faixa Ribeira (SW de São Paulo, NE do Paraná), se comparado ao que se observa na porção NE (Estados do Rio de Janeiro e Espírito Santo).

\section{METODOLOGIA}

\section{Concentração da monazita}

Amostras de rocha de grande volume (5 - $8 \mathrm{~kg}$ ) foram britadas em britador de mandíbulas de aço e quarteadas para extração de uma alíquota de $100 \mathrm{~g}$ para análises químicas e isotópicas. O material britado foi moído em um moinho de discos; o espaçamento entre os discos foi sendo diminuído gradualmente, e a fração inferior a 80 mesh foi sendo extraída após peneiramento, para liberar os cristais de minerais acessórios antes que eles fossem fragmentados.

O primeiro $1,5 \mathrm{~kg}$ com granulação abaixo de 80 mesh foi levado a uma mesa de Wiffley para concentração dos minerais pesados. Da fração mais pesada, que tipicamente tinha massa inferior a 20 - $30 \mathrm{~g}$, foi feita concentração adicional 
dos minerais pesados utilizando-se separação magnética (separador Frantz) e por líquido pesado (iodeto de metileno). O concentrado final foi separado em frações magnéticas em separador Frantz; no equipamento utilizado, a monazita concentrou-se na fração magnética no intervalo entre 0,5 e $0,85 \mathrm{~A}$, com inclinação lateral de $10^{\circ}$ e vertical de $15^{\circ}$.

\section{Dissolução e análise}

\section{Procedimento de abertura da monazita}

O grão selecionado para análise é transferido para um béquer Savillex ${ }^{\circledR}$ de $7 \mathrm{ml}$, pré-limpo por três noites utilizando-se $\mathrm{HCl}$ e $\mathrm{HNO}_{3}$ ultrapuros, contendo $\mathrm{HNO}_{3} 7$ N. Após cerca de 1 hora, é feita lavagem da amostra alternadamente com água Milli-Q e $\mathrm{HNO}_{3} 7 \mathrm{~N}$ com o auxílio de uma pipeta. Ao final, adicionam-se duas gotas de $\mathrm{HNO}_{3} 7 \mathrm{~N}, 6 \mu \mathrm{lde}$ $\mathrm{H}_{2} \mathrm{SO}_{4}$ e $5 \mu \mathrm{l}$ de spike ${ }^{205} \mathrm{~Pb}-{ }^{235} \mathrm{U}$. O béquer é fechado e levado a chapa aquecedora a $150^{\circ} \mathrm{C}$ por três dias; ao final, é aberto e aquecido até quase secura completa.

\section{Procedimento de extração de $\mathrm{U}$ e $\mathrm{Pb}$ em minicolunas de troca iônica}

A extração de $\mathrm{U}$ e $\mathrm{Pb}$ é feita em mini-colunas de troca iônica carregadas com 3 gotas de resina Eichrom 1 x 8 . O procedimento tem início com a lavagem da coluna, alternadamente com $\sim 210 \mu 1$ (7 gotas) de água Milli-Q e de $\mathrm{HCl} 6 \mathrm{~N}$. A resina é então condicionada com $120 \mu \mathrm{l}$ de $\mathrm{HCl}$ $3 \mathrm{~N}$, e a amostra, dissolvida em $60 \mu$ l, é depositada na coluna. $\mathrm{U}$ e $\mathrm{Pb}$ são coletados em $200 \mu \mathrm{l}$ de água Milli-Q após a extração dos demais constituintes em $90 \mu \mathrm{l}$ de $\mathrm{HCl} 3 \mathrm{~N}$ e $120 \mu \mathrm{l}$ de $\mathrm{HCl} 6 \mathrm{~N}$. À solução contendo U e Pb adiciona-se uma gota de ácido fosfórico, e então ela é seca em chapa aquecedora, resultando em uma gota que será posteriormente dissolvida para deposição no filamento.

\section{Análise espectrométrica e redução dos dados}

Para análise espectrométrica os concentrados de $\mathrm{U}$ e $\mathrm{Pb}$ foram depositados em filamentos de Re. A análise foi feita em espectrômetro Finnigan modelo 262. Na maioria dos casos, o sinal obtido para o $\mathrm{Pb} 206$ foi superior a $40 \mathrm{mV}$, possibilitando análises com boa precisão em detectores Faraday, que permitem a análise simultânea dos isótopos 205, 206 e 207 do $\mathrm{Pb}$; o isótopo $204 \mathrm{~Pb}$ foi sempre medido em contador iônico. Nos casos em que o sinal era mais fraco, todos os isótopos de $\mathrm{Pb}$ e $\mathrm{U}$ foram medidos em contador iônico.
${ }^{208} \mathrm{~Pb},{ }^{207} \mathrm{~Pb}$ e ${ }^{206} \mathrm{~Pb}$ radiogênicos foram calculados após a correção de branco e $\mathrm{Pb}$ inicial não-radiogênico de acordo com o modelo Stacey \& Kramers (1975) para a idade aproximada da amostra. Os brancos obtidos no período de análises variaram entre 30 e $120 \mathrm{pg}$ de $\mathrm{Pb}$ total. As constantes de decaimento usadas foram $0.155125 \times 10^{-9} \mathrm{ano}^{-1}$ para ${ }^{238} \mathrm{U}$ e $0.98485 \times 10^{-9}$ ano $^{-1}$ para ${ }^{235} \mathrm{U}$. A regressão dos dados foi feita utilizando o programa ISOPLOT de Ludwig (1993); as incertezas nas razões isotópicas na Tabela 1 são dadas ao nível de confiança de $2 \sigma$.

\section{RESULTADOS OBTIDOS}

\section{Batólito Natividade da Serra}

(amostra E-00-13: 744208N ; 50657E)

O batólito Natividade da Serra, com área exposta superior a $800 \mathrm{~km}^{2}$, é uma das mais expressivas ocorrências graníticas do leste paulista, mas não foi até o momento alvo de nenhum estudo específico. Mostra-se alongado na direção ENE (Figura 1), com uma unidade de borda em que predominam biotita granitos porfiríticos e um núcleo mais diferenciado, de (turmalina)-muscovita-biotita granito equigranular branco; corpos de granada-turmalina aplito e pegmatito são comuns, especialmente no núcleo do batólito (Chiodi Filho et al., 1983; Fernandes, 1991).

A única estimativa de idade para o batólito deve-se a Tassinari (1988), que obteve, isócrona $\mathrm{Rb}-\mathrm{Sr}$ (pelo método de Williamson) de $570 \pm 50$ Ma. Claramente, é desejável obter uma idade mais precisa para o batólito.

A amostra estudada provém da unidade de borda no extremo leste do batólito, a sul de Cunha (SP), e corresponde a um biotita granito porfirítico orientado, com muscovita e turmalina. Forneceu abundantes cristais de monazita límpida, idiomórfica, de cor amarelo brilhante. Três determinações $\mathrm{U}-\mathrm{Pb}$ foram obtidas nesses cristais (Tabela 1). Duas delas (\# 4, \# 5) são concordantes a 586 - $587 \mathrm{Ma}$. Um segundo cristal da fração $\mathrm{m}(0,5)$ (\# 3) tem idade ${ }^{207} \mathrm{~Pb} /{ }^{206} \mathrm{~Pb}$ mais elevada $(612 \pm 5 \mathrm{Ma})$, que pode refletir alguma herança, mas trata-se do resultado de pior qualidade, em vista do baixo valor de ${ }^{206} \mathrm{~Pb} /{ }^{204} \mathrm{~Pb}$ medido.

A idade de cristalização magmática do batólito é aqui interpretada como a idade média das frações concordantes (587 $\pm 7 \mathrm{Ma})$, o que é confirmado por análises de uma segunda amostra (E-00-17a, $c f$. localização na Figura 1) e por datações independentes de cristais de monazita de ambas as amostras por EPMA, que mostram ainda a superposição de um evento de recristalização de monazita a ca. 525 Ma no batólito (Vlach et al., 2002). 


\section{Batólito Serra do Quebra-Cangalha (amostra E-00-7; 746561N; 48860E)}

Outra expressiva ocorrência de rochas graníticas no leste paulista ainda pouco estudada, o batólito Serra do Quebra-Cangalha é referido na literatura apenas em trabalhos de cunho regional. Como no caso do batólito Natividade da Serra, a principal variação composicional se dá entre biotita granitos porfiríticos e muscovita-biotita granitos equigranulares mais diferenciados, em parte com granada.

A amostra escolhida para separação mineral é um muscovita-biotita granito branco inequigranular grosso com IC $=5$ coletado pouco a sul de Guaratinguetá (Figura 1). A amostra forneceu grande quantidade de cristais de monazita, concentrados nas frações magnéticas no intervalo entre 0,5 e 0,85 A. Parte dos cristais é límpida, de cor amarela de brilho vítreo intenso. No entanto, aparecem também muitos cristais leitosos e xenomórficos, especialmente na fração menos magnética.

Os cristais escolhidos para análise são límpidos, brilhantes e idiomórficos. As duas frações analisadas mostram-se um pouco discordantes, e têm idades ${ }^{207} \mathrm{~Pb} /{ }^{206} \mathrm{~Pb}$ diferentes, mas elevadas para o padrão regional $(681 \pm 5$ e $656 \pm 4 \mathrm{Ma})$. Não é possível por ora definir as razões para a diferença observada. Outras duas frações estão sendo analisadas para se obter um resultado mais preciso para a idade desta amostra. A idade mais antiga é consistente com valores obtidos através de datações pontuais por EPMA na mesma amostra (dados inéditos de S. Vlach), o que parece sugerir que os valores mais baixos refletem processos de recristalização.

\author{
Maciço Santa Branca \\ (amostra E-00-22a; 740793N, 40998E)
}

O maciço Santa Branca aparece em mapas regionais como uma intrusão alongada, em parte interdigitada com micaxistos encaixantes, a aparentemente intrusiva no maciço Santa Catarina, aflorante a SW (Figura 1). Foi estudado por Alves (1975) e Theodorovicz et al. (1990), que reportam o predomínio de muscovita-biotita granito branco equigranular médio em parte foliado.

A amostra escolhida para datação provém de blocos cortados para extração de paralelepípedos expostos na rodovia que liga Jacareí a Santa Branca. Trata-se de um biotita granito branco equigranular com $\mathrm{IC}=5$, homogêneo, com pequena proporção de muscovita, baixa susceptibilidade magnética $\left(\mathrm{k}=0,05 \times 10^{-3} \mathrm{SI}\right)$, e foliação de estado sólido definida pelo alinhamento das lamelas de biotita. Forneceu pequena quantidade de cristais de monazita, em sua maioria leitosos; os poucos cristais transparentes correspondem a fragmentos.

Os resultados analíticos mostram-se fortemente discordantes (Tabela 1), o que é pouco comum na análise de cristais de monazita. Tal fato é atribuído a reações de transformação da monazita em agregados de apatita + allanita + epidoto, observadas em seções petrográficas. Desta forma, acredita-se que parte dos cristais analisados corresponda a esses sobrecrescimentos, formados por minerais cujas estruturas têm baixa retentividade para o $\mathrm{Pb}$. Uma das frações analisada (\# 8), a menos discordante, tem elevada incerteza, e idade ${ }^{207} \mathrm{~Pb} /{ }^{206} \mathrm{~Pb}$ notavelmente baixa $(527 \pm 12 \mathrm{Ma})$. As

Tabela 1. Resultados de determinações isotópicas U-Pb para monazita de granitos peraluminosos do leste do Estado de São Paulo.

\begin{tabular}{|c|c|c|c|c|c|c|c|c|c|c|c|c|c|}
\hline Amostra & $\begin{array}{c}\text { Massa } \\
(\mathrm{mg})\end{array}$ & $\begin{array}{c}\text { Fração } \\
\text { magnética }\end{array}$ & $\begin{array}{c}\text { Medido } \\
{ }^{206} \mathrm{~Pb} / \\
{ }^{204} \mathrm{~Pb}\end{array}$ & $\begin{array}{c}\text { Corrigido } \\
{ }^{206} \mathrm{~Pb} / \\
{ }^{238} \mathrm{U}\end{array}$ & $\begin{array}{r}\text { Erro } \\
(\%) \\
\end{array}$ & $\begin{array}{c}\text { Corrigido } \\
{ }^{207} \mathrm{~Pb} / \\
{ }^{235} \mathrm{U}\end{array}$ & $\begin{array}{r}\text { Erro } \\
(\%) \\
\end{array}$ & $\begin{array}{c}\text { Corrigido } \\
{ }^{207} \mathrm{~Pb} / \\
{ }^{206} \mathrm{~Pb} \\
\end{array}$ & Rho & $\begin{array}{c}\text { Idades } \\
{ }^{206} \mathrm{~Pb} / \\
{ }^{238} \mathrm{U}\end{array}$ & $\begin{array}{c}(\mathrm{Ma}) \\
{ }^{207} \mathrm{~Pb} / \\
{ }^{235} \mathrm{U} \\
\end{array}$ & $\begin{array}{l}{ }^{207} \mathrm{~Pb} / \\
{ }^{206} \mathrm{~Pb}\end{array}$ & $\begin{array}{l}\text { Erro } \\
\text { (Ma) }\end{array}$ \\
\hline E-00-07 & 0,027 & 0,5 & 230,13 & 0,1051 & 0,59 & 0,9007 & 0,64 & 0,0622 & 0,928 & 644,3 & 652,1 & 679,3 & 5,1 \\
\hline E-00-07 & 0,006 & 0,7 & 836,95 & 0,1035 & 1 & 0,8769 & 1,02 & 0,0615 & 0,172 & 634,7 & 639,29 & 655,6 & 3,7 \\
\hline E-00-13 & 0,026 & 0,5 & 235,81 & 0,094 & 0,72 & 0,7811 & 0,76 & 0,0602 & 0,9463 & 579,4 & 586,1 & 612,3 & 5,3 \\
\hline E-00-13 & 0,013 & 0,5 & 2102,6 & 0,0942 & 1,05 & 0,7727 & 1,11 & 0,059 & 0,957 & 580,2 & 581,3 & 585,6 & 7 \\
\hline E-00-13 & 0,012 & 0,75 & 597,71 & 0,0949 & 0,79 & 0,7788 & 0,82 & 0,0595 & 0,9668 & 584,3 & 584,8 & 587 & 4,6 \\
\hline E-00-22 & 0,006 & 0,6 & 470,33 & 0,0757 & 0,58 & 0,6093 & 0,5 & 0,0584 & 0,965 & 328,2 & 360,7 & 544,1 & 3,4 \\
\hline E-00-22 & 0,005 & $0.7 \mathrm{~A}$ & 837,62 & 0,0839 & 1 & 0,6702 & 1,15 & 0,0579 & 0,8815 & 519,4 & 520,8 & 527,2 & 12 \\
\hline $\mathrm{E}-00-22$ & 0,007 & 0,7 & 272,07 & 0,0586 & 0,52 & 0,4729 & 0,58 & 0,05925 & 0,987 & 367 & 393,2 & 550,8 & 5,7 \\
\hline E-00-25 & 0,022 & 0,7 & 420,3 & 0,0522 & 1,97 & 0,4267 & 2,01 & 0,0592 & 0,9862 & 328,2 & 360,9 & 576,3 & 7,2 \\
\hline
\end{tabular}




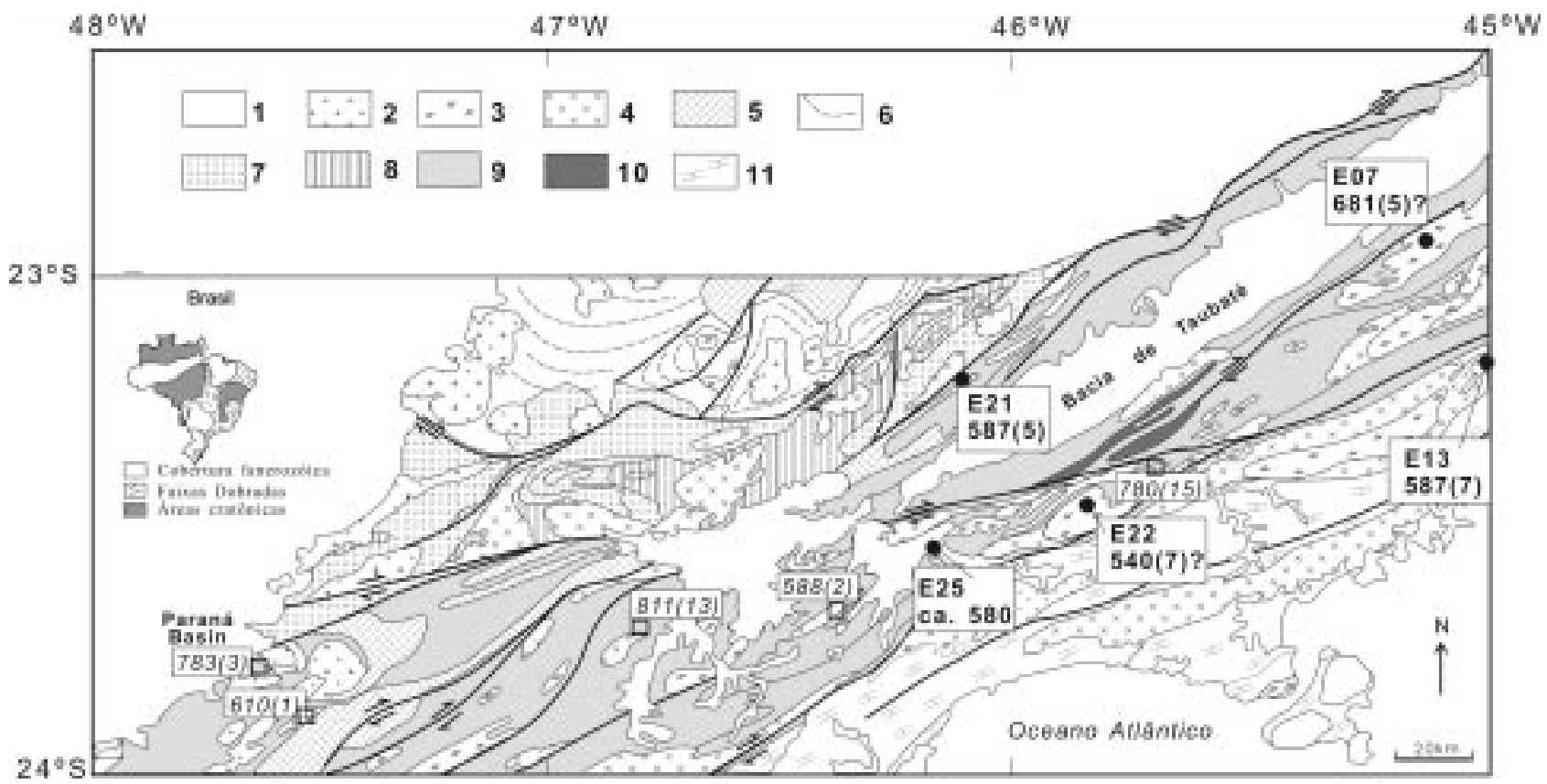

Figura 1. Mapa geológico esquemático da porção leste do Estado de São Paulo, destacando as ocorrências de granito (modificado de Campos Neto, 2000). Números ao lado da identificação das amostras (E13, E25 etc) correspondem às idades $\mathrm{U}-\mathrm{Pb}$ e erros $(2 \sigma)$, em milhões de anos.

1 - cobertura sedimentar e intrusivas fanerozóicas; 2 - granitos tardi- e pós-orogênicos, Província Itu (ca. 590 - 570 Ma); granitos sin-orogênicos (3 a 5): $\mathbf{3}$ - (granada)-(muscovita)-biotita granitos; 4 - biotita granitos porfiríticos; 5 - hornblendabiotita granitos; 6 - Nappe Socorro-Guaxupé (predomínio de paragnaisses migmatíticos); 7 - Grupo São Roque (predomínio de metapelitos e metapsamitos de baixo grau metamórfico); 8 - Grupo Serra do Itaberaba (seqüências metavulcanosedimentares de médio grau metamórfico); Domínio Embu (9 a 10): 9 - metasupracrustais de baixo e médio grau metamórfico, respectivamente Complexos Pilar do Sul e Embu; 10 - gnaisses migmatíticos; embasamento Paleoproterozóico a Arqueano; 11 - Complexo Costeiro (migmatitos orto e paraderivados).

outras duas frações têm idades ${ }^{207} \mathrm{~Pb} / 206 \mathrm{~Pb}$ semelhantes; uma regressão forçada a zero dessas frações resulta em idade $\mathrm{U}-\mathrm{Pb}$ de $540 \pm 5 \mathrm{Ma}$ (Figura 2). Embora seja possível que os valores baixos obtidos reflitam um evento de recristalização pós-magmática de monazita, à semelhança do que foi observado no batólito Natividade da Serra, destaca-se que não existem indícios de idade superior a 550 Ma nas três frações analisadas. Uma nova amostra do maciço deverá ser alvo de datação para confirmar se a idade obtida é a idade de cristalização magmática, pois em caso afirmativo ela corresponderia a uma das idades $\mathrm{U}-\mathrm{Pb}$ mais jovem obtidas até o momento para granitos no Estado de São Paulo, apenas comparável àquela obtida para os turmalina granitos de Perus.

\section{Maciço Mogi das Cruzes}

(amostra E-00-25a; 739453N; 38039E)

O maciço Mogi das Cruzes é uma pequena ocorrência de muscovita-biotita granito equigranular branco médio a grosso, maciço, com IC $\sim 5$ aflorante nos arredores da cidade homônima, e ainda hoje explorado como pedra de revestimento.

Na pedreira onde foi coletada a amostra aqui estudada, são comuns enclaves microgranulares félsicos finos (riolíticos), com fenocristais de feldspato alcalino capturados do granito, e xenólitos de mica-xisto e de gnaisse cálcio-silicático, estes últimos em parte envolvidos por pegmatitos turmaliníferos. 
Figura 2. Diagrama concórdia U-Pb reunindo todas as amostras estudadas neste trabalho. É mostrada na Figura a regressão das frações \# 7 e 9 do maciço Santa Branca. Para idade das demais amostras, ver texto.

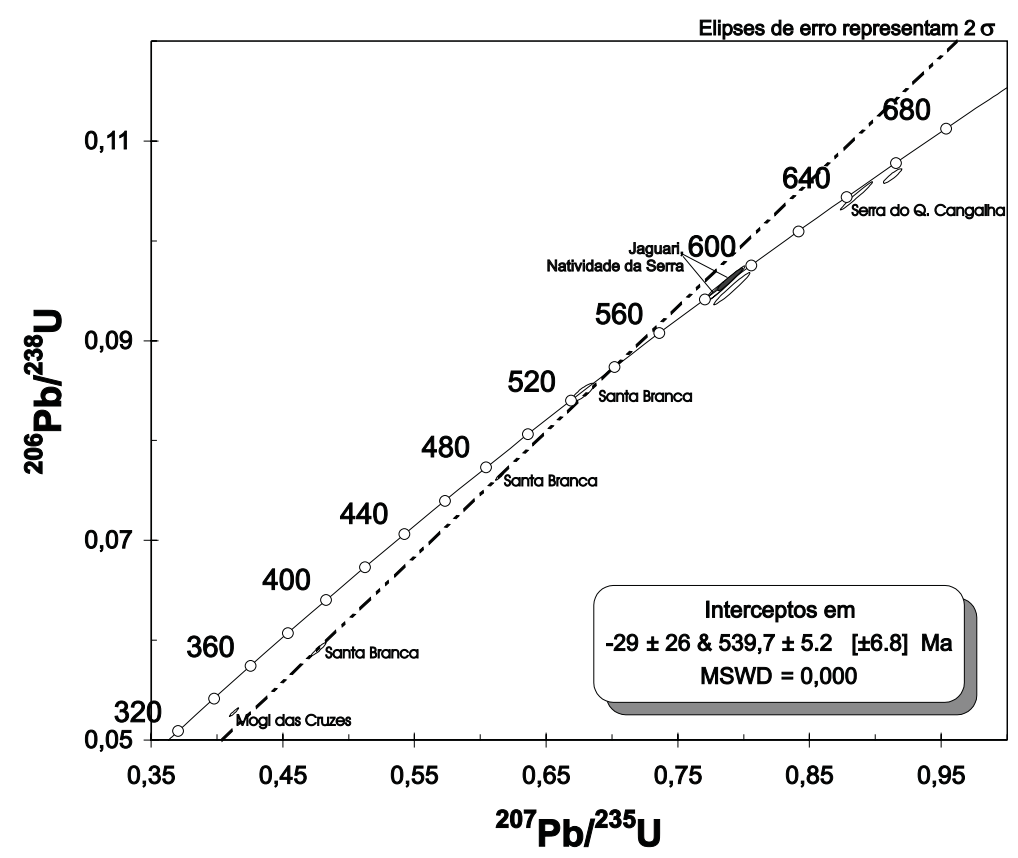

A amostra E-00-25a forneceu pequena quantidade de cristais de monazita, todos invariavelmente foscos e leitosos. Apenas uma fração forneceu resultado $\mathrm{U}-\mathrm{Pb}$ adequado, e fortemente discordante (\# 10, Tabela 1; idade ${ }^{207} \mathrm{~Pb} /{ }^{206} \mathrm{~Pb} \sim 580 \mathrm{Ma}$ ). Provavelmente, assim como na amostra do maciço Santa Branca, a forte discordância está relacionada à presença de elevado número de inclusões de apatita em alguns grãos e de produtos de reação da monazita no cristal analisado, como observado em imagens de elétrons retroespalhados na microssonda. Dados de microssonda para monazita e xenotima coexistentes apontam para idades em torno de 590 ( $\pm 12 \mathrm{Ma}$ ) (Vlach, 2002). Assim, embora o resultado isotópico obtido carregue elevada incerteza, em vista da discordância, uma idade de cristalização próxima a 580 - 590 Ma pode ser indicada. Este valor encontra-se dentro do intervalo observado em outras ocorrências vizinhas, como o maciço Mauá (e. g., Filipov \& Janasi, 2001; cf. Figura 1).

\section{Maciço Jaguari}

(amostra E-00-21; 742572N, 37401E)

O maciço Jaguari corresponde a um corpo de ortognaisse extremamente estirado que aflora junto à Falha de Jundiuvira, no limite setentrional do Domínio Embu, pouco a norte de Santa Isabel (Figura 1). Foi mapeado por Motidome (1992), que individualizou esta ocorrência de leucogranitos peraluminosos miloníticos, com forte lineação de estiramento mineral subhorizontal paralela à foliação ENE-SSW da rocha em meio a augen-gnaisses metaluminosos (a hornblenda + biotita + titanita) igualmente deformados, que correspondem aos gnaisses de Santa Isabel, aparentemente equivalentes aos gnaisses do Butantã de Coutinho (1972).

A amostra estudada é da facies de menor IC ( 2), um biotita-muscovita ortognaisse que aparentemente invadiu uma facies inequigranular mais rica em biotita $(\mathrm{IC}=5)$. Em vista do teor baixo de máficos, partiu-se de uma amostra inicial grande $(c a .8 \mathrm{~kg}$ ), que forneceu boa quantidade de cristais de monazita, em geral límpidos e transparentes. Apenas um cristal foi analisado, obtendo-se resultado praticamente concordante e com incerteza relativamente baixa (587 $\pm 5 \mathrm{Ma}$ ). A faixa onde se situa o granito gnáissico Jaguari foi afetada por intenso cisalhamento, com o desenvolvimento de lineação definida por minerais de facies anfibolito. Não existem estudos específicos que determinem se a intrusão do maciço é contemporânea ou anterior ao cisalhamento, mas acredita-se que, dada à temperatura elevada em que ele ocorreu, a idade obtida corresponda à idade desse cisalhamento. Na hipótese de que o granito tenha se colocado previamente ao cisalhamento, ele poderia ser comparável ao granito Turvo, datado por Janasi et al. (2001) em $610 \mathrm{Ma}$, que invade granitos metaluminosos aparentemente equivalentes não deformados dos augen-gnaisses Santa Isabel. 


\section{EVOLUÇÃO DO MAGMATISMO GRAN ÍTICO}

\section{Metamorfismo e ortognaisses a $\sim 790-780 \mathrm{Ma}$}

Referências a idades U-Pb no intervalo 800 - 780 Ma na porção central da Faixa Ribeira são recentes (Vlach, 2001; Cordani et al., 2002). Na porção sul da Província Mantiqueira, esse intervalo corresponde à geração de granitos e rochas vulcânicas juvenis no arco magmático Vila Nova (Babinski et al., 1996). Um evento metamórfico e de geração de granitos desta idade encontra-se também caracterizado na Faixa Brasília (Ferreira et al., 1994; Pimentel et al., 2000).

Datações Th-U-Pb $\mathrm{T}_{\mathrm{T}}$ em monazita por EPMA obtidas por Vlach (2001) mostram que o metamorfismo principal em facies anfibolito no Domínio Embu ocorreu há $790 \pm 20$ Ma, valor obtido em Sil-Grt-Bt-Ms xistos e gnaisses de ambas as regiões a oeste e leste da cidade de São Paulo.

Cordani et al. (2002) obtiveram idade U-Pb por SHRIMP em zircão de $811 \pm 13$ Ma em biotita gnaisse granodiorítico aflorante a SW da cidade de São Paulo, interpretada como a idade da cristalização do protólito ígneo da rocha, para o qual sugeriram origem associada ao desenvolvimento de um arco magmático continental.

Vlach (2001) obteve idades $\mathrm{U}-\mathrm{Th}-\mathrm{Pb}_{\mathrm{T}}$ próximas a $790 \mathrm{Ma}$ por EPMA em monazita e xenotima de biotita ortognaisses tonalíticos e granodioríticos, interpretados como intrusões peraluminosas sin-orogênicas, aflorantes nas proximidades da represa Paraibuna, a sul de São José dos Campos (Figura 1).

Um ortognaisse protomilonítico aflorante na borda do maciço granítico Serra dos Lopes, a oeste de Piedade (Figura 1) foi datado por TIMS na Universidade de Alberta, Canadá, por R. J. Leite (tese em conclusão), que obteve a idade de $783 \pm 3$ Ma em monazita e zircão. A rocha tem composição química peculiar, que alia um teor relativamente alto de minerais ferromagnesianos, alto $\mathrm{Ba}$ e $\mathrm{Sr}$ (foi comparada a magmas shoshoníticos por Campos Neto et al., 1990) e caráter francamente peraluminoso, refletido na abundância de muscovita modal.

Em resumo, um evento de metamorfismo e reciclagem da crosta continental a 790 - 780 Ma no Domínio Embu encontra-se hoje claramente definido, embora seu significado tectônico seja ainda incerto. Inexistem estudos geoquímicos devotados aos granitóides datados até o momento, e as características comuns entre eles são o seu caráter peraluminoso e a quantidade de minerais máficos por vezes relativamente alta. Essas características lembram os granitos tipo $\mathrm{S}$ australianos, cujo caráter mais primitivo deve-se em parte à incorporação de restitos provenientes de protólitos metassedimentares (White \& Chappell, 1988). Por outro lado, admite-se atualmente que parte do caráter máfico desses granitos deriva da participação de um componente basáltico derivado do manto em sua gênese (Barbarin, 1999; Patiño Douce, 1999). No caso dos granitóides do Domínio Embu, pouco pode ser especulado quanto à participação de material derivado do manto em sua gênese; de qualquer forma, os teores elevados de Ba e Sr da ocorrência da Serra dos Lopes requerem um componente rico em LILE que poderia estar em porções enriquecidas do manto.

\section{Magmatismo a ca. $680 \mathrm{Ma}$}

Embora ainda carente de melhor refinamento, a idade de ca. 680 Ma obtida preliminarmente para o batólito Serra do Quebra-Cangalha é singular no quadro evolutivo regional. Não se conhecem idades de boa qualidade para rochas graníticas desta ordem na porção central da Faixa Ribeira. Determinações $\mathrm{U}-\mathrm{Pb}$ recentes têm mostrado que o magmatismo sin-orogênico na Nappe Socorro-Guaxupé teve início a 660 - $640 \mathrm{Ma}$, faixa de idades que tem sido obtida para uma série de ortognaisses (Ebert et al., 1995; Janasi, 1999; Negri, 2002; Hackspacher et al., 2003), que foram sucedidos pela geração profusa de granitos a 630 - $620 \mathrm{Ma}$ (Topfner, 1996; Janasi, 1999). No caso do Domínio Embu, contudo, o período sin-orogênico foi mais jovem (variando diacronicamente entre 610 e $590 \mathrm{Ma}$, ver adiante), e não se conhecem até o momento precursores significativamente mais antigos.

A existência de eventos de geração de rochas a 680 Ma, contudo, é sugerida pela presença de núcleos herdados de monazita e zircão em um granito peraluminoso do maciço tardi-orogênico Piedade, observada tanto em determinações por TIMS (Janasi et al., 2001) como por EPMA (Vlach \& Gualda, 2000).

\section{Magmatismo sin-orogênico a $\sim 610 \mathrm{Ma}$}

As principais manifestações plutônicas neoproterozóicas da porção central da Faixa Ribeira são os três expressivos batólitos alongados segundo NE-SW que se estendem na região entre os estados de São Paulo e Paraná (Agudos Grandes, Três Córregos e Cunhaporanga, Figura 1). Determinações $\mathrm{U}-\mathrm{Pb}$ recentes indicam idades no intervalo 615 - 610 Ma para a cristalização do maior volume de corpos graníticos no interior desses batólitos, incluindo os hornblenda-biotita granitos porfiríticos que predominam em todos eles (Gimenez Filho et al., 2000; Janasi et al., 2001; Prazeres Filho, 2000). 
O maciço granítico Turvo é uma intrusão alongada formada por leucogranitos a duas micas em parte portadores de granada e turmalina, que invadem hornblenda-biotita granitos da porção oriental do batólito Agudos Grandes. Idade U-Pb em monazita obtida por TIMS na Universidade do Kansas é bastante precisa $(610 \pm 1 \mathrm{Ma})$, mas indistinguível da idade dos granitos cálcio-alcalinos potássicos dominantes (610 \pm 2 Ma; Janasi et al., 2001).

Os granitos tipo Turvo mostram todas as características de típicos produtos de anatexia crustal. Como indicado por seu caráter félsico e mineralogia peraluminosa, devem refletir eventos de fusão de metassedimentos induzidos pelo intenso fluxo térmico associado à invasão dessa crosta pelos magmas que deram origem aos grandes batólitos cálcioalcalinos alongados. Os magmas que deram origem aos granitos sin-orogênicos do batólito Agudos Grandes se deslocaram significativamente na crosta, invadindo rochas encaixantes relativamente frias, que registram evento(s) metamórfico(s) prévio(s). Não se conhecem até o momento registros de metamorfismo a $\sim 610$ Ma nesta porção da Faixa Ribeira.

\section{Magmatismo sin-orogênico a $\sim 590 \mathrm{Ma}$}

O intervalo entre 590 e 565 Ma corresponde ao pico do metamorfismo e do magmatismo sin-orogênico na Faixa Ribeira à altura dos Estados do Rio de Janeiro e do Espírito Santo (Campos Neto \& Figueiredo, 1995; Machado et al., 1996), em claro contraste com o que se observa na região à oeste da cidade de São Paulo ( $c f$. item precedente), revelando o caráter diacrônico do evento térmico principal ao longo da faixa.

A idade de formação do batólito Natividade da Serra, uma das mais expressivas manifestações graníticas do Domínio Costeiro no Estado de São Paulo (587 $\pm 5 \mathrm{Ma}$, U-Pb em monazita; ver também Vlach et al., 2002), situa-se exatamente nesse intervalo, que também parece corresponder à idade do metamorfismo principal nesse domínio (Dias Neto, 2001; S. Vlach, dados inéditos).

Duas das manifestações graníticas situadas no Domínio Embu a leste da cidade de São Paulo estudadas neste trabalho, ambas de porte relativamente pequeno, fornecem idades U-Pb em monazita no intervalo 580 - $590 \mathrm{Ma}$ (maciços Mogi das Cruzes e Jaguari). A elas, junta-se a idade U-Pb em monazita do maciço granítico Mauá, vizinho ao de Mogi das Cruzes, apresentada por Filipov \& Janasi (2001).

\section{Granitos mais jovens}

A idade U-Pb em monazita obtida no presente trabalho para o maciço Santa Branca ( $540 \mathrm{Ma})$, se confirmada, alinha-se, junto à do granito Perus, como a mais jovem determinada até o momento para granitos do Estado de São Paulo. Este evento seria contemporâneo à cristalização do granito Getulândia, de afinidades não-orogênicas (tipo A), situado na divisa entre os estados de São Paulo e Rio de Janeiro (Machado et al., 1996), e mais jovem que o granito Serra da Batéia, também de tipo A, e intrusivo no batólito Agudos Grandes (Janasi et al., 2001).

\section{CONSIDERAÇÕES FINAIS}

A determinação da idade de granitos peraluminosos através da datação de monazitas por TIMS tem sido bastante utilizada, em vista da facilidade de obtenção e dos resultados favoráveis. As análises aqui apresentadas estão entre as primeiras obtidas de modo sistemático no CPGeo, e lograram obter alguns resultados significativos. Em casos favoráveis, precisões da ordem de $\pm 1 \mathrm{Ma}(2 \sigma)$ podem ser obtidas para granitos neoproterozóicos, o que permite resolver de modo adequado eventos geológicos pouco separados no tempo. O estudo paralelo dos cristais de monazita em petrografia convencional e através de imageamento por microscopia eletrônica e datações Th-U-Pb ${ }_{\mathrm{T}}(e . g$., Vlach $\mathrm{e}$ Gualda, 2000) é altamente desejável, pois revela que as idades obtidas por TIMS não serão sempre de interpretação fácil, e em alguns casos podem mesmo não ter significado. Casos de herança isotópica são relativamente raros, mas processos de recristalização pós-magmática parecem bastante freqüentes. Em alguns casos, esses processos podem gerar idades mistas (por vezes concordantes) intermediárias entre os dois eventos ( $c f$. Vlach et al., 2002); em outros, surgem produtos de reação com baixa retentividade para o $\mathrm{Pb}$ (e. g., apatita, allanita), resultando em idades fortemente discordantes.

As idades obtidas neste e em outros trabalhos recentes para granitos peraluminosos da porção central da Faixa Ribeira revelam que sucessivos eventos de reciclagem da crosta continental ocorreram ao longo de $c a .200$ milhões de anos, com pelo menos quatro eventos bem marcados a 780 - 800, ca. 680 - 650, 610 e 590 - $580 \mathrm{Ma}$; possivelmente, um evento ainda mais jovem, a $c a$. 540 Ma resultou na formação do maciço Santa Branca.

\section{AGRADECIMENTOS}

Os autores agradecem à FAPESP que através do Auxílio à Pesquisa 00/2509-8 financiou as análises U-Pb apresentadas neste trabalho. Ao CNPq, pela concessão de Bolsa PIBIC a Adriana Alves. Ao Prof. Dr. Miguel Basei e aos 
técnicos do laboratório U-Pb do CPGeo, em especial Vasco A. P. Laias, Cláudia Regina Passareli, Valter Sproesser e Kei Sato pelo apoio na obtenção dos dados. Ao Dr. Allen Fetter e ao Prof. Dr. Peter C. Hackspacher pelo apoio no uso das facilidades do laboratório de preparação de amostras para análises isotópicas da UNESP, em Rio Claro, SP. Agradecem também a revisão crítica de dois relatores anônimos desta revista.

\section{REFERÊNCIAS BIBLIOGRÁFICAS}

ALVES F. R. (1975) Contribuição à geologia da região de Salesópolis-Guararema, SP. São Paulo, 138 p. Dissertação (Mestrado) - Instituto de Geociências, Universidade de São Paulo.

BABINSKI, M.; CHEMALE JR., F.; VAN SCHMUS, W. R.; HARTMANN, L. A.; SILVA, L. C. (1996) Juvenile accretion at 750-700 Ma in southern Brazil. Geology, v. 25, n. 5, p. 439-442.

BARBARIN, B. (1999) A review of the relationships between granitoid types, their origin and geodynamic environments. Lithos, v. 46, p. 605-626.

CAMPOS NETO, M. C. (2000) Orogenic systems from Southwestern Gondwana: an approach to Brasiliano-Pan-African cycle and orogenic collage in Southeastern Brazil. In: CORDANI, U. G.; MILANI, E. J.; THOMAZ FILHO A.; CAMPOS D. A. (eds.) Tectonic evolution of South America. Rio de Janeiro, p. 335-365.

CAMPOS NETO, M. C., FIGUEIREDO, M. C. H. (1995) The Rio Doce orogeny, Southeastern Brazil. Journal of South American Earth Sciences, v. 8, n. 2, p. 143-162.

CAMPOS NETO, M. C.; BERGMANN, M.; SIGA JR., O.; FIGUEIREDO, M. C. H. (1990) Geologia da folha Pilar do Sul, escala 1:25.000. São Paulo, IGUSP/PRÓ-MINÉRIO. (Relatório Final). v. 1.

CHIODIFILHO, C.; CHIEREGATI, L. A.; THEODOROVICZ, A. M. G.; THEODOROVICZ, A.; MENEZES, R. G.; RAMALHO, R.; BATOLLAJR., F. (1983) Geologia e recursos minerais das Folhas Natividade da Serra e Caraguatatuba. In: JORNADA SOBRE ACARTA GEOLÓGICADOESTADODE SÃOPAULO em 1:50.000, 1., São Paulo, 1983. Atas. São Paulo, Pró-Minério. p. 8-30.

CORDANI, U. G.; COUTINHO, J. M. V.; NUTMAN, A. P. (2002) Geochronological constraints on the evolution of the Embu Complex, São Paulo, Brazil. Journal of South American Earth Sciences, v. 14, p. 903-910.

COUTINHO J. M. V. (1972) Petrologia do pré-Cambriano em São Paulo e arredores. Boletim do Instituto de
Geociências e Astronomia-USP, v. 3, p. 5-99.

DIAS NETO, C. M. (2001) Evolução tectono-termal do complexo costeiro (faixa de dobramento Ribeira) em São Paulo. São Paulo, 160p. Tese (Doutorado) - Instituto de Geociências, Universidade de São Paulo.

EBERT, H. D.; CHEMALI JR., F.; BABINSKI, M.; ARTUR, A. C.; VAN SCHMUS, W. R. (1995) Tectonic setting and $\mathrm{U} / \mathrm{Pb}$ zircon dating of the plutonic Socorro Complex in the transpressive Rio Paraíba do Sul shear belt, SE Brazil. Tectonics, v. 15, n. 2, p. 688-699.

FERNANDES, A. J. (1991) O complexo embu no leste do Estado de São Paulo- contribuição ao conhecimento da litoestratigrafia e da evolução estrutural $e$ metamórfica. São Paulo, 120 p. Dissertação (Mestrado) - Instituto de Geociências, Universidade de São Paulo.

FERREIRA FILHO, C. F.; KAMO, S. L.; FUCK, R. A.; KROGH, T. E.; NALDRET, A. J. (1994) Zircon and rutile $\mathrm{U}-\mathrm{Pb}$ geochronology of the Niquelândia layered mafic and ultramafic intrusion, Brazil: constraints for the time of magmatism and high grade metamorphism. Precambrian Research, v. 68, p. 241-255.

FILIPOV, M.; JANASI, V. A. (2001)The Mauá granitic massif, Central Ribeira Belt, São Paulo: petrography, geochemistry and $\mathrm{U}-\mathrm{Pb}$ dating. Revista Brasileira de Geociências, v. 31, p. 341-348.

GIMENEZ FILHO, A. (1993) Evolução do Complexo Granítico de Três Córregos, a noroeste de Apiaí- SP. São Paulo, 118 p. Dissertação (Mestrado) - Instituto de Geociências, Universidade de São Paulo.

GIMENEZFILHOA.; JANASI, V.A., CAMPANHA,G.A.C., TEIXEIRA, W.; TREVIZOLIJR, L. E. (2000) U-Pb dating and $\mathrm{Rb}-\mathrm{Sr}$ isotope geochemistry of the eastern portion of the Três Córregos batholith, Ribeira Fold Belt, São Paulo. Revista Brasileira de Geociências, v. 30, n. 1-3, p. 45-50.

HACKSPACHER, P. C.; FETTER, A. H.; EBERT, H. D.; JANASI, V. A.; DANTAS, E. L., OLIVEIRA, M. A. F.; BRAGA, I. (2003) Magmatismo cálcio-alcalino a 660 - 640 Ma no Domínio Socorro: registros de convergência pré-colisional na aglutinação do gondwana ocidental. Geologia USP. Série Cientifica (submetido).

HASUI, Y.; CARNEIRO, C. D. R.; BISTRICHI, C. A. (1978) Os granitos e granitóides da região de dobramentos sudeste nos Estados de São Paulo e Paraná. In: CONGRESSOBRASILEIRODEGEOLOGIA, 30., Recife, 1978. Anais. Recife, SBG, v. 6, p. 2594-2608.

HEILBRON, M., VALERIANO, C., TUPINAMBÁ, M., VALLADARES, C., DUARTE, B.P., PALERMO, N., SILVA, L.G.E., RAGATKI, D., NETTO, A. M., (1999) Revisão 
da proposta de compartimentação tectônica e modelo evolutivo para o segmento central da Faixa Ribeira. In: SIMPÓSIODE GEOLOGIA DO SUDESTE, 6., São Pedro, 1999. Boletim de Resumos. São Pedro, SBG, p. 6.

JANASI, V. A. (1999) Petrogênese de granitos crustais na Nappe de Empurrão Socorro-Guaxupé (SP-MG): uma contribuição da geoquímica elemental e isotópica. São Paulo, 304 p. Tese (Livre-Docência) - Instituto de Geociências, Universidade de São Paulo.

JANASI, V. A., ULBRICH, H. H. G. J. (1991) Late Proterozoic granitoid magmatism in the State of São Paulo, southeastern Brazil. Precambrian Research, v. 51, p. 351-374.

JANASI, V.A.; LEITE, R. J.; VAN SCHMUS, W. R. (2001)U$\mathrm{Pb}$ chronostratigraphy of the granitic magmatism in the Agudos Grandes Batholith (west of São Paulo, Brazil): implications for the evolution of the Ribeira Belt. Journal of South American Earth Sciences, v. 14, n. 4, p. 363-376.

LUDWIG, K. R. (1993) Isoplot - a plotting and regression program for radiogenic isotope data. Version 2.70. June 9, 1993: revision. U.S.G.S. Open-File Report, n. 91-445. p.1-42

MACHADO, N.; VALLADARES, C.; HEILBRON, M.; VALERIANO, C. (1996) U-Pb geochronology of the central Ribeira belt (Brazil) and implications for the evolution of the Brazilian orogeny. Precambrian Research, v. 79, n. 3-4, p. 347-361.

MOTIDOME, M. J. (1992) Geologia do Complexo Embu na região entre Santa Isabel e Biritiba-Mirim, SP. São Paulo, 173 p. Dissertação (Mestrado) - Instituto de Geociências, Universidade de São Paulo.

NEGRI, F. A. (2002) Petrologia das rochas charnockitograníticas e encaixantes de alto grau associadas na região de São Francisco Xavier, SP. Rio Claro, 404 p. Tese (Doutorado) - Instituto de Geociências e Ciências Exatas, Universidade Estadual Paulista.

PARRISH R. R. (1990) U-Pb dating of monazite and its application to geological problems. Canadian Journal of Earth Sciences, v. 27, p. 1431-1450.

PATIÑO-DOUCE, A. (1999) What do experiments tell us about the relative contributions of crust and mantle to the origin of granitic magmas? In: CASTRO, A.; FERNÁNDEZ, C.; VIGNERESSE, J. L. (eds) Understanding granites: integrating new and classical techniques. London, Geological Society of London. p. 55-75. (Geological Society of London, Special Publications, 168).

PIMENTEL, M.; FUCK, R. A.; BOTELHO, N. F. (2000) Granites and the geodynamic history of the neoproterozoic Brasília belt, Central Brazil: a review. Lithos, v. 46, p. 463-483.

PRAZERES FILHO, H. J. (2000) Litogeoquímica, geocronologia U-Pb e geologia isotópica dos Complexos Graníticos Cunhaporanga e Três Córregos, Estado do Paraná. São Paulo, 180 p. Dissertação (Mestrado) Instituto de Geociências, Universidade de São Paulo.

REIS NETO, J. M. (1994) Faixa Itaiacoca: registro de uma colisão entre dois blocos continentais no Neoproterozóico. São Paulo, 253 p. Tese (Doutorado) Instituto de Geociências, Universidade de São Paulo,.

SATO, K. (1998) Evolução crustal da Plataforma Sul-Americana com base na geoquímica isotópica $\mathrm{Sm-Nd}$. São Paulo, 297 p. Tese (Doutorado) - Instituto de Geociências, Universidade de São Paulo.

SÖELLNER, F.; LAMMERER, B.; WEBER-DIEFENBACH, K. (1987) The Brasiliano Orogenesis: Age determination (Rb-Sr, U-Pb) in the coastal mountain region of Espírito Santo, Brazil. Zentralblatt fur Geologie und Paláontologie, n. 7-8, p. 729-741.

STACEY, J. S.; KRAMERS, J. D. (1975) Approximation of terrestrial lead evolution by a two-stage model. Earth and Planetary Science Letters, v. 26, p. 207-221.

TASSINARI, C. C. G. (1988) As idades das rochas e dos eventos metamórficos da porção sudeste do Estado de São Paulo e sua evolução crustal. São Paulo, 236 p. Tese (Doutorado) - Instituto de Geociências, Universidade de São Paulo.

THEODOROVICZ, A.; YAMATO, A. A.; TAKAHASHI, A. T.; VASCONCELOS, C. S.; SANTARÉM, P. C. ; SILVA, V. A. (1990) Projeto Santa Isabel/Mogi das Cruzes/Mauá. São Paulo, CPRM/Pró-Minério. 194p. (Relatório Final).

TÖPFNER, C. (1996) Brasiliano-granitoide in den bundesstaaten São Paulo und Minas Gerais, Brasilieneiene Vergleichende studie. Münchner Geol. Hefte A, v.17, p.1-258.

TUPINAMBÁ, M. (1999) Evolução tectônica e magmática da Faixa Ribeira na região serrana do estado do Rio de Janeiro. São Paulo, 221 p. Tese (Doutorado) - Instituto de Geociências, Universidade de São Paulo.

VLACH, S. R. F. (2001) Microprobe monazite constraits for an early (Ca. $790 \mathrm{Ma}$ ) Brasiliano orogeny: the Embu Terrane, Southeastern Brazil. In: SOUTH AMERICAN SYMPOSIUM ON ISOTOPE GEOLOGY, 3., Pucón, 2001. Extended Abstract. Pucón, Sociedad Geológica de Chile, p. 265-268. (CD-ROM)

VLACH, S. R. F. (2002) Quimismo e datação Th-U-Pb xenotima e monazita: exemplo do granito Mogi das Cruzes, leste da Faixa Ribeira, SP, e implicações. In: CON- 
GRESSO BRASILEIRO DE GEOLOGIA, 41., João Pessoa, 2002. Boletim de Resumos. João Pessoa, SBG, p. 479.

VLACH, S. R. F.; GUALDA, G. A. R. (2000) Microprobe monazite dating and the ages of some granitic and metamorphic rocks from Southern Brazil. Revista Brasileira de Geociências, v. 30, n. 1, p. 214-218.

VLACH, S. R. F., JANASI, V. A.; ALVES, A. (2002) Sistemática U-Pb de datação de monazita em rochas graníticas: identificação de eventos superpostos no batólito Natividade da Serra pela combinação de TIMS e datação química por microssonda eletrônica. In: CONGRESSO BRASILEIRO DE GEOLOGIA, 41., João Pessoa, 2002. Boletim de Resumos. João Pessoa, SBG, p. 511.

WHITE, A. J. R.; CHAPPELL, B. W. (1988) Some supracrustal (S-type) granites of the Lachlan Fold Belt. Transactions of the Royal Society of Edinburg.Earth Sciences, v. 79, p. 169-181. 